\title{
ANALISIS PENDAPATAN USAHATANI DAN BIAYA POKOK PRODUKSI PADI RAWA LEBAK DI DESA SERIJABO KECAMATAN SUNGAI PINANG KABUPATEN OGAN ILIR
}

\author{
(Farming Income and Main Production Cost of Rice on Lowland Swamp in Serijabo Village Sungai Pinang \\ Sub District Ogan Ilir Regency)
}

Aminah Candra Kasih, Wan Abbas Zakaria dan Maya Riantini

Jurusan Agribisnis, Fakultas Pertanian, Universitas Lampung, Jl. Prof. Dr. Soemantri Brojonegoro No. 1, Bandar Lampung, 35145, e-mail: wanabas.zakaria@fp.unila.ac.id

\begin{abstract}
This research aims at determining the farm income and main production cost of rice on lowland swamp in Serijabo Village Sungai Pinang Sub-District. This field research was conducted in February-March 2019. The location was one of central productions in Sungai Pinang Sub-District. The sample size was 51 rice farmers who were selected using simple random sampling method. The data were analyzed by using farm income and main production cost analysis with 95 percent of confidence level. The study showed that the biggest average production of rice was $4,446.35 \mathrm{~kg}$ per ha per year with the average of farm income of IDR3,655,271.77. The main production cost of rice per kilogram was IDR825,70 over cash costs and IDR3,682.70 per $\mathrm{kg}$ over total costs with 95 percent of confidence level between IDR2,.987.13 per $\mathrm{kg}$ and IDR4,335.80 per $\mathrm{kg}$ of rice.
\end{abstract}

Key words: farming, income, lowland, production cost, rice

\section{PENDAHULUAN}

Pangan merupakan kebutuhan dasar manusia, oleh karenanya penyediaan pangan yang memadai merupakan kewajiban negara. Undang Undang Nomor 18 Tahun 2012 tentang Pangan, menegaskan bahwa pemenuhan kebutuhan dasar itu merupakan bagian dari hak asasi manusia yang dijamin di dalam Undang Undang Dasar Negara Republik Indonesia tahun 1945 sebagai komponen dasar untuk mewujudkan manusia yang berkualitas.

Indonesia memiliki potensi yang sangat baik dalam pengembangan sektor pertanian. Di tingkat internasional, Indonesia merupakan salah satu produsen sekaligus konsumen beras terbesar dunia. Kondisi ini menuntut kreativitas masyarakat Indonesia dalam meningkatkan produksi padi atau minimal produksi padi seimbang dengan kebutuhan konsumsi dalam negeri, sehingga kestabilan produksi dapat menjaga ketahanan pangan nasional (Kementerian Pertanian 2015).

Tanaman padi merupakan tanaman pangan yang penting sebagai makanan pokok masyarakat Indonesia. Produksi padi Indonesia mencapai angka 81,12 juta ton pada tahun 2017. Produksi tersebut didapat dari beberapa sentra produksi padi di Indonesia, yaitu Jawa Timur, Jawa Barat, Jawa Tengah, Sulawesi Selatan, Sumatera Utara,
Sumatera Selatan, Lampung, Sumatera Barat, NTB, dan Kalimatan Selatan.

Permintaan terhadap beras terus meningkat sejalan dengan pertambahan populasi dan kenaikan tingkat pendapatan penduduk. Upaya diversifikasi, baik dari sisi produksi maupun konsumsi pangan yang belum berhasil, menyebabkan sebagian besar masyarakat Indonesia masih sangat tergantung pada satu jenis bahan pangan yaitu beras. Pertambahan produksi beras cenderung lebih kecil dan tidak mampu mengimbangi pertambahan permintaan beras (Badan Pusat Statistik 2018).

Kebutuhan beras domestik yang sangat besar, membuat pemerintah masih melakukan kebijakan impor bahan pangan tersebut. Berdasarkan Badan Pusat Statistik (2018), impor beras pada semester I tahun 2018 telah mencapai 1,12 juta ton yang berarti melonjak 755 persen dibanding semester I tahun 2017. Pada triwulan II tahun 2018, impor beras mencapai 736 ribu ton meningkat 91,84 persen dan melonjak 765 persen dibanding triwulan yang sama tahun 2017.

Presiden Jokowi menerbitkan inpres perberasan yaitu Inpres Nomor 5 Tahun 2015 menggantikan inpres Nomor 3 Tahun 2012 tentang Kebijakan Pengadaan Gabah/Beras dan Penyaluran Beras Oleh Pemerintah. Harga gabah kering panen di tingkat petani pada tahun 2015 Rp3.700 per kg 
lebih tinggi dibandingkan tahun 2014 Rp3.300 per $\mathrm{kg}$. Kenaikan harga gabah mempengaruhi daya beli petani. Perubahan harga, terutama penurunan harga dapat menyebabkan penurunan keuntungan yang diperoleh petani.

Tekanan penduduk yang semakin besar menuntut diperlukannya lahan untuk produksi pertanian di berbagai agroekosistem. Salah satu alternatif pemecahan masalah adalah memanfaatkan lahan rawa lebak. Rawa lebak sebagai areal produksi pertanian khususnya tanaman pangan, mengingat arealnya sangat luas serta pemanfaatannya belum dilakukan secara intensif dan ekstensif (Alihamsyah dan Ar-Riza 2004).

Kabupaten Ogan Ilir merupakan salah satu kabupaten di Provinsi Sumatera Selatan yang memiliki potensi lahan rawa lebak terluas yaitu 61.940 ha dengan rata-rata produksi padi 2-4 ton/ha. Lahan yang sudah dikembangkan seluas 33.986 ha dan lahan yang belum dikembangkan seluas 27.954 ha (Bappenas 2014). Luas lahan rawa lebak yang belum dimanfaatkan merupakan potensi yang bisa dikembangan menjadi areal lahan pangan untuk menyokong produksi pangan nasional.

Desa Serijabo merupakan salah satu desa di Kecamatan Sungai Pinang yang sebagian besar masyarakatnya berusahatani padi rawa lebak. Pengembangan lahan rawa lebak masih menghadapi berbagai kendala, seperti kondisi sosial ekonomi masyarakat serta kelembagaan dan prasarana pendukung yang belum memadai atau bahkan belum ada. Pertanian padi sawah lebak di daerah ini mempunyai banyak tantangan diantaranya usahatani padi lebak hanya diusahakan setahun sekali, sangat tergantung kepada musim, belum memiliki drainase air yang baik, iklim yang kurang menguntungkan, fluktuasi harga, petani masih menggunakan teknik budidaya yang sederhana, dan petani masih menggunakan benih padi dari hasil panen sebelumnya. Penggunaan benih tersebut menyebabkan produktivitas padi masih rendah (Alihamsyah dan Ar-Riza 2004).

Biaya produksi padi rawa lebak terus meningkat, sejalan dengan meningkatnya harga pupuk, harga padi yang fluktuatif, dan sebagian besar petani mempunyai lahan yang relatif sempit menyebabkan keuntungan yang diperoleh petani rendah. Produksi dan produktivitas berperan terhadap peningkatan pendapatan petani. Tingkat harga berlaku merupakan indikator yang mempengaruhi naik turun pendapatan petani, karena harga merupakan salah satu penentu keberhasilan usaha dan tingkat keuntungan petani atas penjualan produknya.

Biaya pokok produksi didapatkan dari jumlah keseluruhan biaya produksi. Biaya produksi secara umum terdiri dari biaya input, biaya tenaga kerja, dan biaya tetap. Umumnya petani kurang memperhatikan dalam menghitung biaya-biaya tersebut, sehingga tidak mengetahui jumlah biaya yang sesungguhnya telah digunakan. Harga pokok produksi sangat berpengaruh dalam perhitungan keuntungan yang akan diperoleh petani dalam suatu proses budidaya pada satu musim tanam.

Berdasarkan uraian permasalahan, penelitian ini bertujuan untuk mengetahui besar pendapatan usahatani padi rawa lebak dan mengetahui biaya pokok produksi padi rawa lebak di Desa Serijabo Kecamatan Sungai Pinang Kabupaten Ogan Ilir.

\section{METODE PENELITIAN}

Penelitian ini menggunakan metode survei di Desa Serijabo Kecamatan Sungai Pinang Kabupaten Ogan Ilir. Pengambilan data dilakukan pada Februari hingga Maret 2019. Lokasi penelitian dipilih secara purposive (sengaja) dengan pertimbangan bahwa Kecamatan Sungai Pinang merupakan salah satu sentra penghasil padi rawa lebak dengan luas panen 3.164 ha. Responden petani padi dipilih secara acak (simple random sampling). Sebelum dilakukan penelitian, terlebih dahulu dilakukan pra survey untuk mengetahui keadaan umum calon responden. Populasi petani padi di Desa Serijabo adalah 987 petani. Berdasarkan perhitungan dengan menggunakan rumus Issac dan Michael dalam Sugiarto (2003) diperoleh jumlah sampel sebanyak 51 orang petani.

Data yang digunakan dalam penelitian ini adalah data primer dan data sekunder. Data primer diambil langsung dari petani padi melalui wawancara langsung menggunakan kuisioner. Data sekunder diperoleh dari sumber yang memiliki keterkaitan dengan permasalahan penelitian seperti Badan Pusat Statistik, Badan Perencanaan Pembangunan Nasional (BAPPENAS) dan Kementerian Pertanian.

Metode analisis yang digunakan adalah metode analisis deskriptif kualitatif dan kuantitatif. Analisis deskristif kuantitatif digunakan untuk mengetahui hasil produksi, harga hasil produksi, jumlah faktor produksi, harga faktor produksi dan tingkat pendapatan. Analisis deskriptif kualitatif 
digunakan untuk menjelaskan hasil yang diperoleh dari analisis kuantitatif.

Analisis pendapatan usahatani digunakan untuk menjawab tujuan pertama. Analisis pendapatan usahatani dihitung dengan menggunakan rumus (Soekartawi 2003) :

$\pi=T R-T C$ atau $\pi=P y . Y-(F C+V C)$.

\section{Keterangan:}

$$
\begin{array}{ll}
\pi & =\text { Pendapatan/keuntungan }(\mathrm{Rp}) \\
\mathrm{TR} & =\text { Penerimaan }(\mathrm{Rp}) \\
\mathrm{TC} & =\text { Biaya total }(\mathrm{Rp}) \\
\mathrm{Py} & =\text { Harga produksi }(\mathrm{Rp} / \mathrm{kg}) \\
\mathrm{Y} & =\text { Jumlah produksi }(\mathrm{Kg}) \\
\mathrm{FC} & =\text { Biaya tetap }(\mathrm{Rp}) \\
\mathrm{VC} & =\text { Biaya variabel }(\mathrm{Rp})
\end{array}
$$

Indikator pengukuran kelayakan usahatani padi menggunakan rumus Return Cost Ratio atau R/C (Soekartawi 1995):

$R / C$ Ratio $=T R / T C$.

Keterangan :

$\mathrm{R} / \mathrm{C}=$ Nisbah penerimaan dan biaya

TR = Total revenue (total penerimaan)

$\mathrm{TC}=$ Total cost (total biaya)

Terdapat tiga kriteria dalam perhitungan ini, yaitu :

a. Jika $\mathrm{R} / \mathrm{C}<1$, maka usahatani yang dilakukan secara ekonomi tidak menguntungkan.

b. Jika $\mathrm{R} / \mathrm{C}>1$, maka usahatani yang dilakukan secara ekonomi menguntungkan.

c. Jika $\mathrm{R} / \mathrm{C}=1$, maka usahatani berada pada titik impas (Break Event Point).

Analisis perhitungan biaya pokok produksi pada penelitian ini digunakan untuk menjawab tujuan kedua. Biaya produksi merupakan biaya yang terjadi untuk mengolah bahan baku menjadi produk jadi yang siap dijual, sedangkan harga pokok merupakan pengorbanan sumber ekonomi untuk memperoleh aktiva (Mulyadi 1991).

Penetapan biaya pokok produksi dilakukan dengan cara menekan biaya produksi serendah mungkin dan tetap menjaga kualitas dari barang atau produk yang dihasilkan, sehingga biaya pokok produk yang dihasilkan perusahaan lebih rendah dari yang sebelumnya (Kusnadi, Tinaprilla, Susilowati, Purwoto 2011). Dalam memperhitungkan unsurunsur biaya ke dalam biaya pokok produksi, terdapat dua pendekatan yaitu full costing dan variable costing. Perhitungan biaya pokok produksi menurut Mulyadi (1991) yang ditunjukan pada Tabel 1.

\section{HASIL DAN PEMBAHASAN}

\section{Karakteristik Petani Responden}

Berdasarkan hasil penelitian diperoleh data bahwa umur petani responden padi berkisar antara 33 hingga 70 tahun, dengan umur rata-rata 48 tahun. Jumlah responden terbanyak ada di kisaran umur antara 46 hingga 58 tahun (43 persen) dari jumlah keseluruhan responden. Hal tersebut menunjukkan bahwa tenaga kerja tergolong usia produktif dan masih mampu ditingkatkan lagi produktivitasnya.

Pendidikan formal petani rata-rata hanya mencapai tingkat menengah atas (SMA). Tingkat pendidikan sebagian besar petani responden adalah SD dengan persentase (45 persen), SMP dengan persentase (35 persen), SMA dengan persentase (18 persen) dan sarjana dengan persentase ( 2 persen).

Lama berusahatani petani responden paling banyak berkisar antara 18 hingga 30 tahun. jumlah

\begin{tabular}{|c|c|c|c|}
\hline No & Uraian & Satuan & Nilai \\
\hline 1. & $\begin{array}{l}\text { Penerimaan } \\
\text { Produksi }\end{array}$ & $\mathrm{Kg}$ & A \\
\hline \multirow[t]{7}{*}{2.} & Biaya Produksi & & \\
\hline & I. Biaya Tunai & & \\
\hline & Benih & $\mathrm{Kg}$ & B \\
\hline & Pupuk & $\mathrm{Kg}$ & $\mathrm{C}$ \\
\hline & Pestisida & $\mathrm{Rp}$ & $\mathrm{D}$ \\
\hline & TK Luar Keluarga & HOK & $\mathrm{E}$ \\
\hline & Total Biaya Tunai & & $\mathrm{F}=\mathrm{B}+\mathrm{C}+\mathrm{D}+\mathrm{E}$ \\
\hline \multirow[t]{8}{*}{3.} & II. Biaya Diperhitungka & & \\
\hline & TK Keluarga & $\mathrm{HOK}$ & G \\
\hline & Penyusutan Alat & $\mathrm{Rp}$ & $\mathrm{H}$ \\
\hline & Pajak & $\mathrm{Rp}$ & I \\
\hline & Sewa Lahan & $\mathrm{Rp}$ & $\mathrm{J}$ \\
\hline & Biaya Lain-lain & $\mathrm{Rp}$ & $\mathrm{K}$ \\
\hline & Bunga Modal & $\mathrm{Rp}$ & $\mathrm{L}$ \\
\hline & $\begin{array}{l}\text { Total Biaya } \\
\text { Diperhitungkan }\end{array}$ & $\mathrm{Rp}$ & $\mathrm{M}=\mathrm{G}+\mathrm{H}+\mathrm{I}+\mathrm{J}+\mathrm{K}$ \\
\hline 4. & III. Total Biaya & $\mathrm{Rp}$ & $\mathrm{N}=\mathrm{F}+\mathrm{L}$ \\
\hline \multirow[t]{4}{*}{5.} & Pendapatan & & \\
\hline & I. Pendapatan Atas & $\mathrm{Rp}$ & $\mathrm{F}-\mathrm{A}$ \\
\hline & Biaya Tunai & & \\
\hline & $\begin{array}{l}\text { II. Pendapatan Atas } \\
\text { Biaya Total }\end{array}$ & $\mathrm{Rp}$ & $\mathrm{N}-\mathrm{A}$ \\
\hline 6. & Biaya Pokok Produksi & $\mathrm{Rp}$ & N/A \\
\hline
\end{tabular}
tanggungan keluarga petani responden sebagian besar adalah 0-2 jiwa (4 persen), selanjutnya 3-4 jiwa (43 persen), dan 5-6 jiwa (12 persen).

Tabel 1. Perhitungan biaya pokok produksi usahatani padi di Kecamatan Sungai Pinang Kabupaten Ogan Ilir, 2018 
Jumlah anggota keluarga sesuai norma keluarga kecil bahagia sejahtera (NKKBS) yaitu berkisar dari 1 sampai dengan 4 orang.

\section{Keragaan Usahatani Padi}

Bertani merupakan pekerjaan utama petani responden padi dalam memenuhi kebutuhan hidup. Tanaman padi di daerah penelitian ditanam secara monokultur. Petani hanya melakukan penanaman padi sebanyak satu kali dalam satu tahun. Waktu penanaman tidak dilakukan serempak oleh petani, sehingga menyebabkan waktu panen menjadi tidak bersamaan. Sebagian besar petani melakukan penanaman padi pada bulan Februari hingga Maret, sedangkan pemanenan dilakukan pada bulan Juni hingga Juli setiap tahunnya untuk lahan rawa lebak dangkal.

Budidaya padi yang dilakukan oleh petani dimulai dengan persemaian, pengolahan tanah, pemindahan I, pemindahan II, penanaman, penyiangan, pemupukan, pengendalian HPT, pemanenan hingga pasca panen. Benih yang digunakan merupakan benih yang berasal dari musim tanam sebelumnya, sehingga menyebabkan produktivitas padi masih rendah, berkisar 2-4 ton/ha. Produktivitas yang efektif padi rawa lebak menurut Balai Besar Penelitian Tanaman Padi dalam Jamil, Satoto, Sasmita dan Guswara (2016) berkisar 6-8 ton/ha. Hal ini berarti produktivitas padi di Desa Serijabo masih rendah dibandingkan dengan produktivitas yang seharusnya.

\section{Biaya Usahatani Padi}

Setiap kegiatan usahatani tidak pernah terlepas dari biaya untuk mengelolah usahatani, agar memperoleh hasil yang diharapkan. Biaya yang dimaksud meliputi biaya tetap dan biaya variabel. Biaya tetap adalah biaya yang besar kecilnya tidak dipengaruhi oleh volume produksi, sedangkan biaya variabel adalah biaya yang besar kecilnya dipengaruhi oleh volume produksi. Kontribusi biaya paling besar adalah untuk biaya tenaga kerja dan biaya sewa lahan. Biaya rata-rata sewa lahan yang dikeluarkan oleh petani untuk kegiatan usahatani dalam satu tahun adalah sebesar $\mathrm{Rp}$. 3.039.008,39 per hektar per tahun, sedangkan ratarata biaya tenaga kerja sebesar Rp6.260.882,35 per tahun.

\section{Analisis Pendapatan Usahatani Padi}

Pendapatan usahatani adalah selisih antara total penerimaan dikurangi dengan total biaya yang dikeluarkan oleh petani. Biaya yang dikeluarkan petani dibedakan menjadi biaya tunai dan biaya total. Biaya tunai merupakan biaya yang benarbenar dikeluarkan oleh petani dalam usahatani padi seperti biaya benih, biaya pupuk, biaya pestisida, dan biaya tenaga kerja. Biaya total adalah biaya keseluruhan yang mencakup biaya tunai dan biaya diperhitungkan (biaya tenaga kerja dalam keluarga, biaya penyusutan peralatan usahatani, sewa lahan, pajak, dan biaya lain-lain). Tingkat pendapatan usahatani padi rawa lebak disajikan pada Tabel 2.

Tabel 2 menunjukkan bahwa pendapatan usahatani padi petani responden atas biaya total sebesar $\mathrm{Rp}$ 3.415.474,81 per hektar. Nisbah penerimaan terhadap biaya total pada usahatani padi adalah sebesar 1,20 artinya setiap Rp 1,00 biaya total yang dikeluarkan akan menghasilkan penerimaan sebesar Rp1,20. Nisbah penerimaan terhadap biaya total yang lebih besar dari 1,00 menunjukkan bahwa usahatani padi di Desa Serijabo Kecamatan Sungai Pinang secara ekonomi menguntungkan dan layak untuk diusahakan.

Pendapatan atas biaya tunai yang diperoleh petani sebesar Rp16.433.020,41 per tahun per hektar, dari pendapatan tersebut diperoleh pendapatan per bulan sebesar Rp1.369.418,37. Nilai pendapatan tersebut lebih kecil jika dibandingkan dengan pendapatan per kapita penduduk pedesaan menurut BPS (2018) sebesar Rp 400.000,00 per orang. Rata-rata anggota keluarga petani Desa Serijabo berjumlah 4,75 orang. Jika pendapatan tersebut dibagi dengan jumlah rata-rata anggota keluarga diperoleh jumlah pendapatan $\mathrm{Rp}$ 288,29 per kapita per orang. Nilai pendapatan tersebut lebih kecil dari petani responden, karena usahatani padi dilakukan satu kali dalam satu tahun, artinya usahatani padi rawa lebak yang dijalankan belum mampu mensejahterakan petani.

Penelitian ini sejalan dengan penelitian Sari dan Febriyansyah (2018) yang menyatakan penerimaan rata-rata per tahun diperoleh sebesar Rp21.081.300,00 sehingga diperoleh pendapatan rata-rata sebesar Rp15.021.854,53, jika pendapatan dibagi dengan jumlah hari selama satu tahun, diperoleh pendapatan Rp42.900,00/hari. Tingkat pendapatan tersebut lebih kecil dibandingkan dengan tingkat upah yang berlaku sebesar $\mathrm{Rp}$ $60.000,00$. Jika produksi dan harga jual gabah semakin tinggi, maka akan meningkatkan penerimaan. 
Tabel 2. Perhitungan rata-rata biaya, pendapatan, dan R/C, usahatani padi di Desa Serijabo Kecamatan Sungai Pinang

\begin{tabular}{|c|c|c|c|c|c|c|c|}
\hline \multirow{3}{*}{ No. } & \multirow{3}{*}{ Uraian } & \multicolumn{6}{|c|}{ Lahan rawa lebak dangkal } \\
\hline & & \multicolumn{4}{|c|}{ Per $\mathbf{0 , 5 3}$ ha } & \multicolumn{2}{|c|}{ Per 1 ha } \\
\hline & & Satuan & Harga (Rp) & Jumlah & Nilai (Rp) & Jumlah & Nilai (Rp) \\
\hline 1 & Penerimaan & & & & & & \\
\hline \multirow[t]{18}{*}{2} & $\begin{array}{l}\text { Produksi Padi } \\
\text { Biaya Produksi }\end{array}$ & $\mathrm{Kg}$ & $4.500,00$ & $2.370,39$ & $10.666 .764,71$ & $4.472,44$ & 20.125.971,14 \\
\hline & Biaya Tunai & $\mathrm{Rp}$ & & & $1.957 .263,89$ & & $3.692 .950,73$ \\
\hline & Benih & $\mathrm{Kg}$ & $4.790,00$ & 2,84 & $13.618,63$ & 5,36 & $25.695,52$ \\
\hline & Pupuk Urea & $\mathrm{Kg}$ & $5.214,29$ & 44,94 & $234.336,13$ & 84,79 & $442.143,65$ \\
\hline & Pupuk Bio Organik & Liter & $61.980,39$ & 0,85 & $52.744,10$ & 1,61 & $99.517,17$ \\
\hline & Pupuk Phonska & $\mathrm{Kg}$ & $4.278,95$ & 20,00 & $85.578,95$ & 37,74 & $161.469,71$ \\
\hline & Insektisida & Liter & & & $31.315,69$ & & $59.086,20$ \\
\hline & Fungisida & Liter & & & $14.322,35$ & & $27.023,31$ \\
\hline & Herbisida & Liter & & & $48.681,37$ & & $91.851,65$ \\
\hline & TK Luar Keluarga & HOK & $60.000,00$ & 21,29 & $1.277 .647,06$ & 40,18 & $2.410 .654,83$ \\
\hline & Sewa Lahan & $\mathrm{Rp}$ & & & $199.019,61$ & & $375.508,69$ \\
\hline & Biaya Diperhitungkan & $\mathrm{Rp}$ & & & $6.899 .299,17$ & & $13.017 .545,60$ \\
\hline & Benih & $\mathrm{Kg}$ & $4.881,71$ & 19,14 & $93.422,48$ & 36,11 & $176.268,83$ \\
\hline & Penyusutan Alat & $\mathrm{Rp}$ & & & $270.058,82$ & & $509.544,94$ \\
\hline & TKDK & HOK & $60.000,00$ & 83,05 & $4.983 .235,29$ & 156,71 & $9.402 .330,74$ \\
\hline & Sewa Lahan & $\mathrm{Rp}$ & & & $1.425 .490,20$ & & $2.689 .604,14$ \\
\hline & Bunga Modal & $\mathrm{Rp}$ & & & $127.092,38$ & & $239.796,95$ \\
\hline & Biaya Total & & & & $8.856 .563,05$ & & $16.710 .496,33$ \\
\hline \multirow[t]{3}{*}{3} & Pendapatan & & & & & & \\
\hline & Atas Biaya Tunai & $\mathrm{Rp}$ & & & $8.709 .500,82$ & & $16.433 .020,41$ \\
\hline & Atas Biaya Total & $\mathrm{Rp}$ & & & $1.810 .201,65$ & & $3.415 .474,81$ \\
\hline \multirow[t]{3}{*}{4} & $\mathrm{R} / \mathrm{C}$ Rasio & & & & & & \\
\hline & Atas Biaya Tunai & & & & 5,45 & & 5,45 \\
\hline & Atas Biaya Total & & & & 1,20 & & 1,20 \\
\hline
\end{tabular}

Hasil ini sesuai dengan penelitian Lumintang (2013) dengan judul Analisis Pendapatan petani padi di Desa Teep Kecamatan Langonan Solo, menyatakan bahwa besar kecilnya pendapatan usahatani padi rawa yang diterima oleh petani dipengaruhi oleh penerimaan dan biaya produksi.

Pendapatan usahatani tersebut masih relatif kecil, terutama jika diperhitungkan dengan proses produksi dalam usahatani, mulai dari pengolahan lahan sampai panen yang rata-rata mencapai 4 bulan. Untuk meningkatkan pendapatan dapat dilakukan dengan penggunaan sarana produksi seperti benih dan pupuk yang bersubsidi, sehingga dapat mengurangi biaya produksi. Hasil penelitian Nugraha, Ridwan, Safaruddin dan Sutrisno (2007) yang berjudul Analisis Model Pengolahan Padi, menyatakan petani yang mengusahakan tanaman padi dengan menggunakan benih padi bersertifikat hasil panen yang diperoleh lebih besar dibandingkan petani yang menggunakan benih yang tidak bersertifikat.

Tabel 3 menunjukkan bahwa biaya pokok produksi padi sebesar Rp825,7 per $\mathrm{kg}$ atas biaya tunai, sedangkan perhitungan atas biaya total sebesar Rp3.736,33 per kg. Penelitian ini sejalan dengan penelitian Zuhairoh (2015) dengan judul Analisis Penentuan Harga Pokok Beras Dengan Menggunakan Metode Full Costing pada Usahatani Beras di Kecamatan Undaan Kabupaten Kudus menggunakan metode full costing, harga yang diperoleh sebesar Rp3.284,00 per kg.

Laba yang diperoleh petani berdasarkan harga pembelian pemerintah Rp5.600,00 lebih besar dari harga pokok produksi yang diperoleh. Peningkatan efisiensi berpengaruh terhadap biaya yang lebih kecil untuk memperoleh suatu hasil tertentu, atau dengan biaya tertentu diperoleh hasil yang lebih banyak. Luas lahan petani yang kecil serta minimnya pendapatan petani ikut mempengaruhi daya beli masyarakat. Pemerintah sebaiknya membuat suatu kebijakan untuk mengurangi ongkos sewa dan tenaga kerja, sehingga meningkatkan pendapatan.

Hasil perhitungan rata-rata selang kepercayaan usahatani padi sebesar Rp3.025,96 dan Rp4.396,20. Hal ini berarti pabrik maupun pemerintah sebaiknya menetapkan harga minimum padi sebesar Rp4.396,20 per kg. Batas maksimum digunakan, agar petani tidak mengalami kerugian dalam berusahatani padi. 
Tabel 3. Perhitungan biaya pokok produksi padi rawa lebak.

\begin{tabular}{|c|c|c|c|c|c|}
\hline No & Jenis input dan lainnya & Satuan & Harga (Rp) & Jumlah & Total \\
\hline 1 & Produksi padi & $\mathrm{kg}$ & $4.500,00$ & $2.370,39$ & $10.666 .764,71$ \\
\hline \multirow[t]{18}{*}{2} & Biaya Produksi & & & & \\
\hline & Biaya Tunai & $\mathrm{Rp}$ & & & $1.957 .263,89$ \\
\hline & Benih & $\mathrm{kg}$ & $4.790,00$ & 2,84 & $13.618,63$ \\
\hline & Pupuk Urea & $\mathrm{kg}$ & $5.214,29$ & 44,94 & $234.336,13$ \\
\hline & Pupuk Bio Organik & liter & $61.980,39$ & 0,85 & $52.744,10$ \\
\hline & Pupuk Phonska & $\mathrm{kg}$ & $4.278,95$ & 20,00 & $85.578,95$ \\
\hline & Insektisida & liter & & & $31.315,69$ \\
\hline & Fungisida & liter & & & $14.322,35$ \\
\hline & Herbisida & liter & & & $48.681,37$ \\
\hline & TK Luar Keluarga & $\mathrm{HOK}$ & $60.000,00$ & 21,29 & $1.277 .647,06$ \\
\hline & Sewa Lahan & $\mathrm{Rp}$ & & & $199.019,61$ \\
\hline & Biaya diperhitungkan & $\mathrm{Rp}$ & & & $6.899 .299,17$ \\
\hline & Benih & $\mathrm{kg}$ & $4.881,71$ & 19,14 & $93.422,48$ \\
\hline & Penyusutan Alat & $\mathrm{Rp}$ & & & $270.058,82$ \\
\hline & TK Dalam Keluarga & HOK & $60.000,00$ & 83,05 & $4.983 .235,29$ \\
\hline & Sewa Lahan (milik) & $\mathrm{Rp}$ & & & $1.425 .490,20$ \\
\hline & Bunga Modal & $\mathrm{Rp}$ & & & $127.092,38$ \\
\hline & Biaya Total & $\mathrm{Rp}$ & & & $8.856 .563,05$ \\
\hline \multirow[t]{3}{*}{3} & Biaya pokok produksi & & & & \\
\hline & Atas Biaya Tunai & $\mathrm{Rp}$ & & & 825,71 \\
\hline & Atas Biaya Total & $\mathrm{Rp}$ & & & $3.736,33$ \\
\hline
\end{tabular}

Perhitungan biaya pokok produksi menggunakan selang kepercayaan dapat digunakan sebagai dasar penentuan harga jual oleh petani padi di Desa Serijabo dan para petani dapat menyesuaikan volume produksi untuk meningkatkan pendapatan.

Tabel 4. Biaya pokok produksi padi rawa lebak menggunakan selang kepercayaan 95 persen

\begin{tabular}{clcr}
\hline No & \multicolumn{1}{c}{ Uraian } & Satuan & \multicolumn{1}{c}{ Nilai (Rp) } \\
\hline 1 & Produksi & $\mathrm{Kg}$ & $2.370,39$ \\
2 & Biaya Total & $\mathrm{Rp}$ & $16.710 .496,33$ \\
3 & Biaya Pokok & $\mathrm{Rp} / \mathrm{kg}$ & $3.711,08$ \\
4 & Biaya Pokok Produksi & & \\
& Atas Biaya Tunai & $\mathrm{Rp} / \mathrm{kg}$ & 825,71 \\
& Atas Biaya Total & $\mathrm{Rp} / \mathrm{kg}$ & $3.736,33$ \\
5 & Selang Kepercayaan 95\% & & \\
& Batas Bawah & $\mathrm{Rp}$ & $3.025,96$ \\
& Batas Atas & $\mathrm{Rp}$ & $4.396,20$ \\
\hline
\end{tabular}

\section{DAFTAR PUSTAKA}

Alihamsyah dan Ar-Riza. 2004. Potensi dan teknologi pemanfaatan lahan rawa lebak untuk pertanian. Makalah Utama. Workshop Nasional Pengembangan Lahan Rawa Lebak. Kerjasama Balai Penelitian Pertanian Lahan Rawa-Pemda Kabupaten Hulu SungaiDinas Pertanian Propinsi Kalimantan Selatan, Kandangan, 11-12 Oktober 2004. [12 Januari 2019].

BAPPENAS [Badan Perencanaan Pembangunan Nasional]. 2014. Rencana Pembangunan Jangka Menengah Nasional (RPJMN) Bidang Pangan dan Pertanian 2015-2019. BAPPENAS. Jakarta.

BPS [Badan Pusat Statistik]. 2018. Statistik Indonesia. http://www.neraca.co.id/article/ 108394/bps-verifikasi-luas-lahan-sawah-disumsel. [25 November 2018].

Kementerian Pertanian. 2015. Outlook Padi. http://www.pertanian.go.id/ap_pages/mod/d atatp. [20 Desember 2018].

Kusnadi N, Tinaprilla N, Susilowati SH dan Purwoto A. 2011. Analisis efisiensi usahatani padi di beberapa sentra produksi padi di Indonesia. Jurnal Agro Ekonomi, 29 (1): 25-48. http://ejurnal.litbang.pertanian. 
go.id/index.pp/jae/article/view/4041/3370.. [20 Desember 2018].

Lumintang FM. 2013. Analisis pendapatan petani padi di Desa Teep Kecamatan Langowan Solo. Jurnal EMBA, 1(3): 991-998. http://ejournal.unsrat.ac.id/index.php/emba/a rticle/download/2304/1858. [5 Desember 2018].

Jamil A, Satoto, Sasmita P dan Guswara A. 2016. Deskripsi Varietas Padi. Balai Besar Penelitian Tanaman Padi. Sukamandi.

Nugraha S, Thahir R, Lubis S dan Sutrisno. 2007. Analisis model pengolahan padi. Jurnal Enjiniring Pertanian, 5 (1): 13-26. http://mekanisasi.litbang.pertanian.go.id/ind/ phocadownload/JEP/analisis_model_pengol ahan_padi_jep_april_2007.pdf. [5 Desember 2018].

Mulyadi. 1991. Akuntansi Biaya. Edisi 5. Universitas Gadjah Mada. Aditya Media. Yogyakarta.
Sari K dan Febriyansyah A. 2018. Produktivitas dan luas lahan minimal petani padi sawah lebak di Kabu paten Ogan Ilir. Jurnal Lahan Suboptimal, 72: 185-195. https://www.jikm. unsri.ac.id/index.php/jlso/article/download/3 54/342. [Oktober 2018].

Sugiarto. 2003. Teknik Sampling. PT Gramedia Pustaka Utama. Jakarta.

Soekartawi. 1995. Analisis Usahatani. Universitas Indonesia Press. Jakarta.

Soekartawi. 2003. Teori Ekonomi Produksi dengan Pokok Bahasan Analisis Fungsi CobbDouglas. PT Raja Grafindo Persada. Jakarta.

Zuhairoh I. 2015. Analisis penentuan harga pokok beras dengan menggunakan metode full costing pada usahatani beras di Kecamatan Undaan Kabupaten Kudus Musim Panen Bulan Juli 2015. Skripsi. Universitas Lampung. Bandar lampung. 